\title{
El gaucho, emblema nacional de la síntesis imposible
}

\author{
Reseña de Adamovsky, Ezequiel (2019). El gaucho indómito. De Martín Fierro a Perón, el emblema \\ imposible de una nación desgarrada. CABA: Siglo XXI, págs. 261
}

\author{
Leandro Nicolás Pankonin \\ leandro_pankonin@yahoo.com.ar \\ Universidad Nacional de General Sarmiento; \\ CONICET, Argentina
}

Cita sugerida: Pankonin, L. N. (2021). El gaucho, emblema nacional de la síntesis imposible [Revisión del libro El gaucho indómito. De Martín Fierro a Perón, el emblema imposible de una nación desgarrada por E. Adamovsky]. Sociohistórica, 47, e135. https:// doi.org/10.24215/18521606e135

Adolfo Prieto publicó en 1988 un libro bello, breve y señero. Después de aquel, nadie pudo volver a hablar del criollismo sin evocarlo. El libro El gaucho indómito. De Martín Fierro a Perón, el emblema imposible de una nación desgarrada, de Ezequiel Adamovsky, también va a la saga de aquel. Sin embargo, es mucho más que eso, por su capacidad de interpelar a El discurso criollista en la formación de la Argentina moderna-como así también a otros clásicos en la materia, como ser El género gauchesco. Un tratado sobre la patria, publicado por Josefina Ludmer en el mismo año que aquel, entre otros-y poner en jaque sus puntos neurálgicos, pero, sobre todas las cosas, por la potencia de las preguntas nuevas que plantea en torno a este problema.

Si Prieto había conjeturado que el fenómeno del criollismo respondió a un fenómeno cultural pasajero, propio de las tensiones de la modernización de fines del siglo XIX y, como tal, los destellos de aquel habrían llegado hasta las puertas de la década de 1920, Adamovsky planteó una hipótesis distinta. Concretamente afirmó que el fenómeno del criollismo, no fue algo pasajero, ni el efecto de apuestas literarias o de intelectuales, pero tampoco una "tradición inventada" desde el Estado. Más aun, su significado más potente fue el de haber expresado "tensiones cruciales" de la "etnogénesis argentina". Es decir, "del proceso por el cual los habitantes que se hallaron viviendo juntos en ese territorio, de orígenes y condiciones enormemente diversos, intentaron construir un sentido de distintividad grupal, el sentido de ser un nosotros". Pero, justamente, lo 
que dicha hipótesis buscó poner sobre la mesa fue el carácter "dislocado e inconcluso" de nuestro "proceso de etnogénesis". A fin de cuentas, lo que Adamovsky identificó en el vértice donde el "gaucho indómito" habita -como "emblema" de la existencia de la nación, al mismo tiempo que como "índice" de sus tensiones y fracturas- es una veta por la cual hacer palpable la imposibilidad de arribar a la estabilización de un "nosotros" nacional, que no por ello deja de existir como tal (pp. 212-218).

Ahora bien, planteado el nudo argumental del trabajo, vale decir algo sobre el modo en el cual el autor arribó hasta allí. Y es en ese plano donde radica la mayor riqueza de la investigación. Su indagación se centró en aquello que denominó como "criollismo popular". En ese sentido definió, en primer término, al "criollismo" como "un modo particular de hablar de lo popular - de la vida del bajo pueblo, de su pasado, de sus aspiraciones de sus valores- a través de la figura del gaucho", y más concretamente al "criollismo popular", como una calificación y un recorte de aquel. Más aun, aquellas producciones de "artistas o escritores de origen popular, o con intención de llegar a un público de clases bajas, o que circuló de manera masiva, sin depender de impulsos estatales". De ese modo, dejó fuera del centro de su indagación a aquellas manifestaciones vinculadas al criollismo "nativista" o "tradicionalismo", que impulsaron las elites y los intelectuales nacionalistas durante la primera mitad del siglo XX (p.13).

Entre la vasta producción del "criollismo popular" de la segunda mitad del siglo XIX, Adamovsky puso especial atención sobre El gaucho Martín Fierro, de José Hernández, a la hora de construir cierto hilo conductor de su exposición. La elección no fue fortuita. La primera parte del poema, publicado en 1872, se convertiría con el tiempo en sinonimia del gaucho y la nación, además de haber impreso sobre el "criollismo popular" uno de sus sentidos primordiales: la crítica social. Al mismo tiempo resultó ser una expresión cabal de la "efectividad cultural de las clases populares", al punto que -como parte de ese mismo derrotero- terminaría por ser canonizado como libro nacional, con especial énfasis a partir de las intervenciones de Leopoldo Lugones en 1913-y la posterior publicación de las mismas en un libro de 1916, titulado El payador-. Así, el autor reconstruyó el modo en que, si bien inicialmente criticada e ignorada por el mundo intelectual, esta obra se ganó la atención de esos sectores de la mano de su éxito de ventas y las crecientes formas de circulación entre "lo alto" y "lo bajo" de la sociedad, así como también gracias a las formas de reoralización dentro del acervo popular, que le dieron mayor vigor. Pero, en sus propios términos, la centralidad del Martín Fierro estuvo dada por varios elementos más. Por un lado, el hecho de haber representado - tal como lo expusimos más arriba- un punto de inflexión fundamental en la propia tradición del criollismo, que arrastraba ya en su haber, para entonces, el hecho de haber sido expresión de la "intersección" entre "lo letrado" y "lo popular" en tiempos de la Revolución de Mayo - de la mano de los cielitos de Bartolomé Hidalgo, que daban paso a que el mundo popular se filtrara en el propio nacimiento de una literatura nacional-; para pasara orbitar, en tiempo de la gobernación de Juan Manuel de Rosas, como un modo de interpelar al pueblo desde cuadrantes ideológicos opuestos, y llegara convertirse, sobre todo luego de la batalla de Caseros -y con la mediación de escritores miembros de las élites letradas-, simultáneamente en expresión de autenticidad nacional y mansedumbre, cuando una inmensa ola inmigratoria llegaría a poblar la Argentina e hicieran falta símbolos locales viables para contener a la diversidad.

Si volvemos al Martín Fierro, el peso que tuvo a partir de su publicación radicó, por un lado, en el hecho de haber traccionado con su éxito un enorme mercado editorial de consumo masivo, y, como parte del mismo proceso -y de las múltiples reconversiones de soportes del desarrollo de la propia cultura masiva argentina durante las siguientes décadas-, el hecho de haberse convertido en una plataforma sobre la cual fue posible leer los vaivenes y resignificaciones a las que fue sujeto el gaucho a través de sus usos. Pero de este dato el autor extrajo un elemento más: la afirmación de que el fenómeno de ventas de Martín Fierro, y más tarde del Juan Moreira de Eduardo Gutiérrez, habría respondido al hecho de que durante décadas la gauchesca política de las gacetas y hojas sueltas había construido un público considerable entre las clases populares. Todo esto se multiplicó en escala con los avances en la alfabetización de esa sociedad. 
Es de resaltar aquí, el modo en el cual Adamovsky propone leer los vaivenes en la representación del gaucho, es decir, cuáles fueron los sentidos que canalizaron sus usos; con qué intencionalidad, y qué es -dada la sinonimia que el gaucho asumió como emblema de la argentinidad- lo que esos usos nos permiten saber acerca de nuestra nación. En ese sentido, procuró mostrar, tanto a través de las producciones del "criollismo popular" como a través de las formas que encontró de hacer asequibles la recepción y el consumo de las mismas, cuáles fueron las disputas sobre el perfil de la nación que el criollismo fue capaz de canalizar. Una veta ingeniosa sobre la cual el autor trabajó a fin de indagar su producción, a través del consumo, fue la reconstrucción biográfica de figuras significativas. Si bien los casos de Martin Castro y Buenaventura Luna merecieron un capítulo cada uno, el recurso valió allí también para hurgar sobre pasajes de otras muchas vidas y las huellas identificables que el "criollismo popular" pudo haberles impreso. Sin ir más lejos, las propias oscilaciones en la trayectoria de José Hernández son un dato a tener en cuenta a la hora de reflexionar sobre las inflexiones de la gauchesca, si tenemos en cuenta la derivación dúctil del propio Martín Fierro entre "la ida" de 1872, y "la vuelta" de 1879 . Hay aquí, sobretodo, una apelación central a la "experiencia" como constructor de sentido del "criollismo popular". En otras palabras, se subraya que es la propia materialidad de la vida la que cargó de sentido e hizo sumamente atrayentes a estas representaciones, en la medida en la que fueron capaces de canalizar y catalizar los imaginarios y las tensiones del mundo real al compás de las cambiantes coyunturas. Si bien esto fue así para el "criollismo popular", cobró un sentido totalmente distinto para un nacionalista conservador como Lugones, que procuró imprimir sobre Martín Fierro la referencia a un "espíritu” venido del pasado, haciendo caso omiso a las desavenencias de un tipo social al que declaró extinto.

Iremos ahora a lo concreto de aquellos sentidos sobre la nación que el "criollismo popular" fue capaz de canalizar, en los términos del autor. Este registro le ha permitido ver el modo en que las clases populares procesaron la llegada masiva de inmigrantes desde finales del siglo XIX, y la enorme heterogeneidad de los orígenes étnicos y los aspectos físicos de aquella sociedad. En otro orden de cosas, el "criollismo popular" funcionó como canal para construir un nosotros como pueblo frente a las clases altas. Pero también canalizó visiones disidentes acerca de la historia nacional. Y, en ese sentido, quizás haciendo pie ahora sí sobre el objetivo central, y como corolario de todo lo anterior, el "criollismo popular" sirvió como canal para tematizar la heterogeneidad étnica del pueblo argentino y la variedad de sus fenotipos, frente a una nación que pretendió ser construida desde sus élites urbanas y porteño-céntricas, sobre el mito de la nación blanca y europea.

El ciclo abordado en este trabajo se cierra con la experiencia de los primeros gobiernos peronistas. Adamovsky dio cuenta de los modos en que el uso del criollismo se intensificó entonces, y funcionó entre otras cosas- como canal para tematizar "la heterogeneidad étnico-racial de la nación". También prestó atención a las formas en que esto se intensificó en esos años por el hecho de ser un fenómeno presente no solo en el bajo pueblo, sino también en los mensajes construidos desde la centralidad del Estado. Así las cosas, sobre los epílogos de ese proceso, con todo lo que aquello trajo a cuenta, ubicó cierto decaimiento de la pregnancia de este fenómeno. En ese sentido, el autor hizo foco sobre el hecho de que el peronismo, al mismo tiempo que asumió la figura del gaucho - mediada por muchos de los sentidos que el "criollismo popular" le imprimió-, produjo también otros emblemas poderosos que le terminaron haciendo sombra: el obrero primero y el "cabecita negra" después. Este último terminaría por absorber varias de las funciones que hicieron atractivo al gaucho como emblema. A saber, "la vinculación con lo rural, lo plebeyo, la Argentina profunda y oprimida y también con lo criollo y no blanco" [203-204]. A esto le sumó el hecho de que existieran cada vez menos personas con memorias o experiencias rurales recientes que las vincularan con lo gauchesco. Pero también la emergencia de una cultura masiva, ahora específicamente orientada a los sectores medios; la irrupción de una cultura juvenil con íconos de rebeldía propios, y el creciente poder que fueron ganando las mujeres en la sociedad de esos años. Esto último entró paulatinamente en tensión con la adulación a la masculinidad que el criollismo desarrolló, no solo bajo el impulso del culto al coraje, el honor y la violencia, sino al mismo tiempo por el hecho de naturalizar la ausencia de las mujeres en esas narrativas, o bien reducirlas siempre a un mero objeto de diputa (pp.203-204). 
Para terminar queremos subrayar dos cosas. En primer lugar señalaremos que se debe poner este libro en la serie de trabajos que buscan contar la historia "desde abajo". Pero, lejos de bogar por una autonomía de "lo popular" o cierto romanticismo inocuo, se hacen presentes aquí aquellas viejas señales del legado bajtiniano que nos recuerdan siempre que la cultura debe ser pensada como un problema dialogal y relacional. $\mathrm{Y}$, en ese sentido, sin esencialismos es que este libro es capaz de afirmar la premisa de que la persistencia del "criollismo popular" expresó, después de todo, ni más ni menos que la dificultad de las clases altas de nuestro país para lograr una hegemonía cultural y política. Y dicha dificultad debe ser entendida, en términos del autor, en tono con "el temprano protagonismo que las clases plebeyas se ganaron en la vida política y que ya nunca perdieron”. Más aun, y sin rodeos, quizás ese sea "un rasgo distintivo” de la historia argentina (p.213). En segundo lugar debemos decir que el trabajo de Adamovsky nos empuja a volver sobre la senda de indagaciones clásicas, y a hacer claro el hecho de que son las preguntas que hacemos y el modo en que las respondemos, aquello que garantiza que una determinada investigación nos permita echar nueva luz sobre los problemas que una sociedad cobija, de manera explícita o latente. El problema de la nación, algo abandonado a mi juicio por las ciencias sociales y humanas de nuestro país, merece volver a ser ponderado como una cuestión en sí misma, para refrescar sobre sí, viejas preguntas, pero también -como aquí sucede- para operativizar nuevas indagaciones que nos permitan tener más y mejores herramientas para trabajar sobre esto que somos, sobre lo que fuimos y sobre lo que queremos ser. 